\title{
SENTENÇA E PROCESSO DE CONHECIMENTO NO DIREITO CIVIL DO ESTADO SOCIAL CONTEMPORÂNEO: REFLEXÕES DE PROCESSO E DIREITO CIVIL-CONSTITUCIONAL
}

\author{
Ricardo Aronne* \\ Marco Félix Jobim**
}

\begin{abstract}
RESUMO
Como é pensado o modelo de fundamentação das decisões judiciais numa sociedade pós-moderna, incerta e complexa? No alvorecer de um novo Código de Processo Civil brasileiro, que aposta num novo modelo de juiz e, portanto, em uma nova fundamentação de suas decisões, os autores apresentam suas reflexões nas áreas do Direito Civil-Constitucional e do Processo, apostando numa leitura em conjunto dos ramos do Direito para o enfrentamento dessas novas questões tão empolgantes que envolve a reforma do Processo Civil brasileiro.
\end{abstract}

PALAVRAS-CHAVE: Direito Civil-Constitucional; Processo Civil; Decisões Judiciais; Pós-Modernidade.

\section{JUDGMENT AND KNOWLEDGE PROCESS IN THE CIVIL LAW OF THE CONTEMPORARY SOCIAL STATE: PROCESS REFLECTIONS AND CIVIL-CONSTITUTIONAL LAW}

\section{ABSTRACT}

How is thought the reasoning model of court decisions in a postmodern society, uncertain and complex? At the dawning of a new Brazilian Civil

* Mestre, Doutor e Pós-doutor em Direito. Professor da graduação e pós-graduação lato e strcito sensu (mestrado e doutorado) da Pontifícia Universidade Católica do Rio Grande do Sul. Advogado.

** Mestre e Doutor em Direito. Professor da graduação e pós-graduação lato e stricto sensu (mestrado) da Pontifícia Universidade Católica do Rio Grande do Sul. Advogado. 
Procedure Code, that promotes a new judge model and, therefore, on a new foundation of its decisions, the authors present their reflections in the Civil-Constitutional Law and Process areas, betting on a joint reading of the Law branches for confronting of these new issues so exciting that involves the reform of the Brazilian Civil Process.

KEYWORDS: Civil-Constitutional Law; Civil Process; Judicial Decisions; Post-Modernity.

\section{INTRODUÇÃO}

Viver é estar num mundo de escolhas! Viver é decidir! E se tivéssemos que motivar todas as decisões tomadas durante o dia, como viveríamos? Isso, pois, o ser humano, diariamente, coloca-se à frente de inúmeras situações nas quais deve exarar uma decisão. Para isso, em muitas delas, deixa de motivar, apenas levando-se ao alvedrio de sua vontade. Há situações, porém, que merecem maiores reflexões, sendo que as escolhas parecem pender para um lado ou outro, quando o fato concreto lhe é relevado. São essas as decisões que nos interessam no presente estudo, e mais, quando são tomadas dentro do processo é o que nos propomos a pensar.

Existem pontos sensíveis da Ciência do Direito, que o acadêmico seguidamente toca e o operador convive, que restam cristalizados na doutrina moderna, ainda assentados sobre pressupostos que já foram corroídos em diversos de seus aspectos e já são percebidos de um modo muito distinto de outrora, mas que persistem sob o mesmo manto original, de ordem notadamente conceitual, mesmo ao serem descritos sob matizes totalmente novos.

Nenhuma das chamadas disciplinas tradicionais do Direito consegue passar incólume por um exame nesse sentido. Ocorre que as vezes esses pontos se escondem em certas esquinas das avenidas do fenômeno jurídico, onde o véu cartesiano da disciplinaridade serve de camuflagem ao tempo.

Um simples olhar interdisciplinar, que nada de novo possui, já é revelador desse horizonte, mas um olhar transdisciplinar pode levar muito além, em uma perspectiva propositiva no âmbito 
crítico dos institutos que demandam ser espanados conforme o tempo a que servem (GLEICK).

A sentença do processo de conhecimento, em sede de Direito Privado contemporâneo, pode ser um farol nesse horizonte de neblina ontológica, amplificada por diversos cantos de metafísicas sereias que anunciam segurança e certeza.

A espiralada víbora da certeza que motivou as codificações paridas pela Chapliniana Modernidade Mecanicista, estava presente do genesis do Code Napoeleon ao paraíso do $B G B$, e se instilou na concepção moderno-tardio de processo de conhecimento, solo onde se construiu a concepção de sentença, aqui em estudo.

E o mesmo fenômeno da complexidade (MORIN), que nos três movimentos da sinfonia do Direito Civil, a Codificação, Descodificação e a Constitucionalização, afastaram ou mitigaram os mecanismos cartesianos de simplificação, com óbvio impacto no principal móbil desse fenômeno, que teve na jurisprudência um intenso protagonismo, parece ter, não raro, na doutrina, um vilão a altura do antagonismo.

Claro que o tema se mostra inesgotável para um breve ensaio e muito mais diante da complexidade que se desdobra de todas as questões aqui tangidas, porém o desafio do texto é justamente colocar o debate, aberto as possibilidades que frutifiquem das idéias daqui germinadas.

\section{SENTENÇA E CERTEZA}

Provavelmente seja muito difícil ao jovem operador do Direito imaginar o dificultoso percurso que as concessões de liminares tiveram no processo civil ocidental continental, no Século XX (CALAMANDREI). Era o lugar da não-certeza e portanto não poderia ter lugar no espaço de certeza prometida pelo processo de conhecimento (SILVA).

Nesse mundo repleto de modernidade, as dicotomias são a pedra fundamental de todas as estruturações de sentido (PRI- 
GOGINE). E é nessa construção de sentido que o processo de conhecimento foi "estruturado" na modernidade, sob um rito que se desenvolve na construção de uma "certeza judiciária", que o próprio século passado viu sucumbir, que teria por corolário a sentença.

0 "fetiche" dessa certeza, ainda um fantasma moderno que ronda as ciências humanas, não constitui mais o núcleo da sentença, mesmo que assim apresente-se nos tradicionais discursos em torno do tema, em especial sob a efígie da propalada "segurança jurídica”. Ainda assim, a sentença não é um espaço complacente a behavearismos ou solipsismos, mesmo para em uma perspectiva de vanguarda (PASQUALINI).

Mas, então, quais seriam os contornos da arquitetura da sentença, em especial no ampliado campo do Direito Privado, democratizado e pluralizado pelo compromisso de eficácia para com os direitos fundamentais ? A superação do formalismo jurídico projeta a discussão até as margens do chamado ativismo judicial e a operação com o sistema jurídico aberto, com o dever de colmatação de lacunas alcançando a atividade judiciária regular, conduzem a temática para outro patamar (FREITAS), promovendo uma decaláge de sentidos e fundamentos em relação a doutrina das primeiras décadas do Século XX.

Desde o relatório, passando pela fundamentação, para alcançar o dispositivo, ainda que por certos aspectos nada tenha mudado na sentença, tudo mudou nesse arco que vai da Modernidade Tardia até a Pós-Modernidade, e muito ainda deve mudar no curso da contemporaneidade.

Como antes referido, qualquer pretensão de completude no tema é um abraçar da mais completa impossibilidade. Assim, o tema será recortado por singulares aqui eleitos, que servirão de arenas aporéticas para análise. 


\section{EPITÁFIOS EM DISPOSITIVOS}

Não é necessária a atenção de um sentinela para perceber que partir a análise do elemento resultante do objeto de estudo traz vigor para implementação do instrumental da desconstrução (DERRIDA), além de revelar de pronto a síndrome que projeta a reflexão jurídica tardio-moderna entre o estruturalismo e o funcionalismo, não raro utilitarista. Descozer a sentença a partir do dispositivo, ao contrário do que tradicionalmente se observa, atenta para as possibilidades que assim se postam, fornecendo novos ângulos de crítica.

O dispositivo sentencial contém a "equação" jurídica que deverá compor a lide, solvendo a demanda. Se o processo de conhecimento tem por objetivo o alcance da sentença, essa última se desenvolve para chegar até o dispositivo como ápice, em uma perspectiva tradicional (ARONNE, 1994). E, conforme a doutrina assentada nessa modernidade, o trânsito em julgado não é do processo, é da sentença; e mais do que da sentença, de sua parte dispositiva (SANTOS). Perceba-se que tampouco isso ficou incólume na contemporaneidade.

Tradicionalmente, assim como cada dia da vida encaminha para a morte, cada movimento do processo conduz para a sentença, ambos finalizando os respectivos dramas; sendo o dispositivo, com trânsito em julgado, o epitáfio que põe termo a história, como se a solução sentencial podesse ser um hay kay da vida.

O pragmatismo que se impôs ao julgador pós-moderno, acredite ele ou não na própria pós-modernidade, de muito puiu discurso de uma verdade sob véus a serem desnudos; porém isso não importa em dizer que uma sentença pode sustentar qualquer coisa em seu dispositivo. 0 sucumbir do determinismo, com a emergência da incerteza que sempre esteve ao lado do discurso científico (HEISENBERG), não abre as portas ao irracionalismo, mesmo que não se ponha à velar o racionalismo iluminista (FOUCAULT). 
Uma percepção indeterminista do Direito, em seu apanágio de Ciência, não quer dizer que não seja determinável o discurso jurídico que alinhava a contemporaneidade (ARONNE, 2006), como sucedeu inclusive com ciências ditas duras, como a Matemática (STEWART) ou a Química e a Física (PRIGOGINE).

A porosidade dos princípios ao mundo da vida, portanto, não se traduz em um vale-tudo-jurídico, onde tudo é e se mostra possível. Claro que diante das possíveis falhas do sistema ou de sua sistematização (HEISENBERG), surpresas sempre são possíveis e devem estar previstas na leitura do Direito, porém são a evidência de uma ruptura. Uma quebra no padrão, que fractalmente (MANDELBROT) se projeta do Direito (ARONNE, 2006).

0 dispositivo sentencial tem aqui um sentido redescoberto, de algum modo. Isso é fruto da complexidade (MORIN) que se apresenta como um novo estatuto do fenômeno jurídico, que desafia a simplicidade cartesiana do modelo moderno, onde o dispositivo desfiava sanções, na concretização de tipos fruto de regras encerradas em um sistema inodoramente fechado aos aromas do mundo dos homens reais, que não se confundem com o "sujeito de direito"ou a pessoas no "físico" ou "jurídico".

Sendo o sistema jurídico formado por regras, princípios (em diversos graus de concreticidade distintas) e valores, na sua imanência e estática, a sentença vai espelhar justamemente seu outro aspecto, o dinâmico, de transcendência, onde o desafio de concretização dessa unidade axiológica, plural de sentidos, encontra um momento especial. Assim como os petitórios, os momentos decisórios são os espaços de "sistematização do sistema" pela sua matemática de revelação, que é o discurso jurídico.

Portanto nesse novo continente normativo, estranho para alguns aspectos do "passado-moderno-jurídico". Não basta esgrimar uma norma jurídica, como outrora, para referendar seu "sentido de aplicação"; as normas demandam concretização e modulação, em especial quando se está tratando de princípios 
jurídicos, cuja abstração é muito variada no ordenamento, mas que invariavelmente demandam o referido discurso para concretizarem-se.

Não basta, pois, no dispositivo sentencial contemporâneo, elencar dispositivos de aplicação. 0 elastério sentencial deverá, sob pena de esvaziar-se, avançar sobre modo de concretização de tais normais e sua eventual modulação em concreto.

\section{RAZÕES ENTRE EMOÇÕES}

Desde VARELA, já se mostra inóquo o corte havido no iluminismo, de ordem cartesiana, mas que aflorou de muitas fontes nos idos da Revolução Científica, cujos ideais ainda são presentes no discurso positivista ainda persistente.

Para além do Pensiéré 33 (PASCAL), que ilumina o recorte capitular desse texto (algum reducionismo cartesiano, portanto), a temática dos valores, esvaziada pelo espiritualismo francês e pelo idealismo alemão, chega muito forte ao Direito, desde o final do século passado (CANARIS). Em sede de sentença, é na ratio decidendi, tema bem usual ao Processo, é que aflora a temática da axiologia dentro do fenômeno jurídico.

Mesmo quando não se trata de um hard case ou de colmatação de lacunas, a sentença já não mais comporta estoicismos ou simplicidade em sede de motivação, diante da complexidade que diariamente desafia o Direito. Ou seja, pode-se chegar a uma solução por diversos meios, porém a escolha dentre esses pode trazer distintos efeitos no caso concreto, até mesmo para terceiros, em tese não alcançados pelo processo.

Daí guardar sentido a discussão instilada pelo NCPC quanto aos efeitos da coisa julgada se estenderem para as razões, enquanto o modelo moderno a restringia ao dispositivo.

As razões da sentença ganham uma importância imensa ao processo, estando nela o núcleo da motivação sentencial, ainda que ali não esteja esse restrito. Interessa que os valores, prenhes 
de concretização e aos princípios, que lhe são intimamente conectados, para além das percepções do reducionismo estruturalista, devem ser enfrentados pelo discurso jurídico.

Reitera-se, mesmo não se tratando de lacuna ou hard case, as razões devem conter as motivações das concretizações que desaguarão no dispositivo, descabendo seja a parte furtada de seu desvelar. É nula a decisão que vulnera isso, sequer sendo o caso de ser reformada em apelação. Vício de motivação nas razões importa em ser emitida uma outra sentença, essa sim integra o suficiente a ser enfrentada por um recurso de apelação. Ignorar isso, com o advento da reforma pela instância recursal, em verdade importa em supressão de um grau recursal e isso é indevido.

Fatos, quando chegam ao processo, importam em valores, já no momento em que se desdobram no âmbito probatório, atingido pelo momento do relatório, mas que aqui perdem a condição discricional, para desbordar ao impressionismo de um quadro de Goya. Afinal, por isso que a prova pertence ao processo e ao mesmo aproveita, não a parte (ARONNE, 1994). Produzida a prova, ela se desliga da parte para interessar ao processo, fundamentando e motivando determinado convencimento (razões) do julgador.

\section{FUNDAMENTAÇÃO DAS DECISÕES JUDICIAIS}

Relatório, fundamentação e dispositivo são partes integrantes do dever do juiz de fundamentar suas decisões, sendo, para ele, um rito (FILARDI) que permite alcançar alguma segurança, será que se pode falar nela em tempo atuais (ÁVILA), e ao jurisdicionado uma ilusão de que ela existirá. Ledo engano! A ritualística (CHASE), embora encontre sua importância, não garante ao julgador, investido em seu corpo dúplice (GARAPON), que decidirá melhor, tampouco ao jurisdicionado que encontrou alguma certeza no direito que agora lhe é conferido pela via jurisdicional. Mas então o que garante alguma segurança no ato de sentenciar com fundamentação, uma vez que faz ela parte 
do seleto rol de Direitos Fundamentais processuais, encontrando morada segura no texto constitucional (CF, art. 93, IX) cuja redação refere que todos os julgamentos dos órgãos do Poder Judiciário serão públicos, e fundamentadas todas as decisões, sob pena de nulidade?

Ora, o caminho que o enunciado direciona é que não existe qualquer julgamento que, sendo prolatado no Poder Judiciário, possa ficar sem a devida fundamentação. 0 que se quer fazer refletir é qual o caminho que deve ser utilizado pelo julgador para fundamentar sua decisão? Essa pergunta é muito pertinente em tempo de separação entre texto e norma (Muller), ou, como prefira-se dizer, da separação entre fonte e norma (Guastini). Em razão da aceitação da doutrina mais atualizada de que texto e norma estão em momentos diferentes, sendo esta o produto da interpretação daquela, é oportuno referir que o texto do artigo 93, IX, CF necessita ser desvelado, autorizando ao intérprete alocar em sua normatização de que o julgador chega a uma fundamentação mais correta a partir de como justifica sua tomada de decisões, chegando-se a conclusão de que fundamentar ou motivar são temas que, apesar de interligados, se apresentam como conceitos diferentes. A grande inovação então do novo texto processual é garantir ao jurisdicionado que o juiz justificará sua decisão em alguns casos. Cabe, agora, ver quas são eles.

\section{JUSTIFICAÇÃO DAS DECISÕES JUDICIAIS NO NOVO CPC}

Em tempos de uma nova codificação processual civil, já tombada sob a numeração de $13.105 / 15$, já era hora de deixar evidenciado, em seu texto, que o dever do juiz não se esvazia no modelo de motivar as decisões, mas sim, a partir dos novos estudos que delinearam os rumos da matéria, de que teria ele o dever de justificar a sua tomada de decisão. A previsão encontra respaldo no artigo 489, $2^{\circ}$, ao aludir no caso de colisão entre normas, o juiz deve justificar o objeto e os critérios gerais da 
ponderação efetuada, enunciando as razões que autorizam a interferência na norma afastada e as premissas fáticas que fundamentam a conclusão.

Note-se: parte-se do pressuposto que é certo que da interpretação do texto possam ser extraídas mais de uma norma para o julgamento do caso apresentado. 0 que diz o referido dispositivo? Nada mais que se o juiz se colocar frente a uma duplicidade de normas, ou ainda mais, tendo em vista que um texto pode ensejar mais do que duas interpretações viáveis, deverá ele justificar o caminho que o levou a escolher uma delas. Qual caminho? Ora, esse será o grande mistério a ser solucionado, uma vez que diferentes marcos teóricos apresentam diferentes formas de se chegar a uma norma. Isso não inibe que mesmo escolhendo diferentes standarts chegue-se a mesma solução, mas, envolvendo o texto mais uma norma, é cediço que deverá o julgador justificar sua tomada de decisão por uma ou outra interpretação.

\section{DECISÕES NÃO-FUNDAMENTADAS: O AVANÇO SOBRE A JURISPRUDÊNCIA}

O profissional do Direito foi, durante os últimos anos, em especial após o texto constitucional, que concedeu acesso irrestrito e gratuito a quem necessitasse ao Poder Judiciário, vergastado de decisões judiciais que tentavam, ao invés de aproximar o cidadão, desestimula-lo de judicializar suas pretensões, uma vez que eram elaboradas sem o devido compromisso constitucional, pois violavam princípios e regras balisadoras do devido processo legal. Uma das violações, por exemplo, era acreditar que o dever de fundamentar se esgotava na mera motivação (THEODORO JÚNIOR, NUNES, BAHIA e PEDRON), ou seja, o preço de uma péssima sentença era "qualquer" motivação. Assim, decisões (interlocutórias, sentenças, acórdãos ou monocráticas) tinham algumas resoluções que não atendiam os ditames constitucionais, como a mera referência a um parecer do Ministério Público, a 
cópia integral da sentença proferida, a decisão que afirmava que o juiz não está vinculado a rebater todos os fatos alegados pelas partes durante o processo e outras mais. Isso, com a ideia de justificação, propicia a mudar, mas mais que isso, com o nova textura processual, algumas dessas decisões estão vedadas ao juiz, sendo, portanto, essas vedações uma conquista do jurisdicionado que repercute em toda cidadania.

Com o intuito de melhor ilustrar, pegue-se a redação do artigo 489 do novo CPC. No caput e incisos, nada de inovação, descrevendo o texto os elementos essenciais da sentença como o relatório, a fundamentação e o dispositivo. Mas, no §1ํㅡ, há uma previsão que influenciará na forma de decicir, pois, refere que não será considerada fundamentada a decisão (quer se esteja falando em interlocutórias, sentenças ou acórdãos) quando:

I - se limitar à indicação, à reprodução ou à paráfrase de ato normativo, sem explicar sua relação com a causa ou a questão decidida; II - empregar conceitos jurídicos indeterminados, sem explicar o motivo concreto de sua incidência no caso; III - invocar motivos que se prestariam a justificar qualquer outra decisão; IV - não enfrentar todos os argumentos deduzidos no processo capazes de, em tese, infirmar a conclusão adotada pelo julgador; V - se limitar a invocar precedente ou enunciado de súmula, sem identificar seus fundamentos determinantes nem demonstrar que o caso sob julgamento se ajusta àqueles fundamentos; VI - deixar de seguir enunciado de súmula, jurisprudência ou precedente invocado pela parte, sem demonstrar a existência de distinção no caso em julgamento ou a superação do entendimento.

Averigue-se que o rol de decisões não-fundamentadas encontra, hoje, resistência pela própria jurisprudência dos mais diversos Tribunais espalhados pelo Brasil. Analisando o inciso IV pode-se elaborar uma pesquisa nos sítios de qualquer tribunal para comprovar que hoje é fato incontestável de que a produção em massa dos acórdãos são complemente contrários ao enunciado legal. Mas, a consciência que se deve criar é de que decisão 
que não enfrenta os argumentos é decisão inválida (DIDIER JR; BRAGA; OLIVEIRA). Ora, modificações legislativas como a ocorrida no processo civil brasileiro denotam que a mudança deverá ocorrer, de igual forma, no profissional do Direito. Sem que esse assuma sua importância no processo de modificação do Direito, muito pouco adiantará uma legislação que aposta, também, na mudança comportamental (THEODORO JÚNIOR, NUNES, BAHIA e PEDRON). O surgimento de um novo modelo processual traz novas responsabilidades cujos sujeitos (melhor seria trabalhar com atores, e o novo CPC peca nesse tópico), constroem, em conjunto, a decisão judicial. E um novo juiz deverá surgir no alvorecer do novo processo civil brasileiro, o que já era reclamo da doutrina (MARINONI) e continua sendo com a chegada do novo CPC (MARINONI; ARENHART; MITIDIERO).

\section{CONSIDERAÇÕES FINAIS}

As presentes considerações, por óbvio necessárias, jamais poderiam postular um encerramento ao tema, centrado em pilares de problematização coerentes ao dasein pós-moderno em que inseri-mo-nos, cientes ou não. Aporeses que se instanciam legitimadas no ser, para muito além de consubstanciações formais, emergem independentemente da escola ou método em que invista o respectivo intérprete ou observador. Desses, a incerteza pode emergir como um elemento de revelação, dentre os demais entre os quais se espirala.

Tomando a decisão de um perfil simplificador, de ordem cartesiana, em paralelo com as equações, diante dos postulados da lógica presente em ambas, pode-se dizer que temas complexos apresentam diversos caminhos para a mesma solução. E a tendência da jurisprudência atual aponta para o enfrentamento cada vez maior de temas complexos no dia-a-dia das cortes brasileiras, em todas suas instâncias. Fenômeno diametralmente oposto ao cotidiano da jurisprudência brasileira do período anterior à redemocratização. 
Não só a sociedade se tornou extremamente complexa, desde os anos 60 do Século XX, como a modificação, na esfera formal e material, na compreensão e aplicação do Direito, em especial a partir da Carta de 88, no que se refere ao Brasil, importaram em profundas mudanças nos decisivos momentos pelos quais percorrem sentenças e acórdãos, que diariamente escrevem os caminhos da senda jurídica, na lavra dos direitos patrimoniais e existenciais jurisdicionados, ora colhendo em boa sofra o compromisso constitucional lavrado pela dignidade da pessoa humana no esteio de um Estado dito democrático e desenhado em relêvo social, na esteira da manutenção de uma economia de mercado compromissada com os direitos fundamentais.

Em tal esteira, a hermenêutica não mais subsidiada em mera aplicação de regras, com imenso papel construtivo no uso tópico de princípios, que retornam ao enlace do corpo jurisprudencial, necessitam elasticida fundamentação para incidência, tal qual se observa nas escolas pretorianas, somente com o trânsito em julgado das respectivas razões é que pode-se imaginar um uso correlato no Brasil. De fato, já verificamos essa prática em diversas cortes nacionais, não obstante muita resistência localizada, com a valorização da fundamentação.

O momento não podia ser mais propício para a identificação do novo modelo de processo civil brasileiro. A comunidade jurídica estava sedenta por mudanças, e elas vieram por um processo lento de transformação social, jurídico e política. Sem os avanços sociais, sem o pleito da sociedade, sem que essa reconhecesse que o processo civil pensado na modernidade não está apto a responder as demandas atuais, nada teria acontecido. Também não fossem os papéis dos Tribunais e pensadores do Direito, as matérias que amanhã se avizinham na nova legislação não seriam passíveis de serem consolidadas no texto. Por fim, sem o papel político realizado nos últimos 5 anos, o processo legislativo teria, quem sabe, arquivado uma lei que necessitava abroxar em um tempo razoável. 
O dever de fundamentação consolida-se como não sendo o mero dever de motivar as decisões judiciais. Vai além! Decidir sem justificar, quando dois ou mais sentidos são possíveis durante a interpretação do texto, não encontra mais respaldo legal. Aliado a esse fato, por si só memorável, o novo CPC constrange o julgador, afirmando que sua postura passiva de resolver casos com decisões já standartizadas não se configuram como prestação jurisdiccional adequada. Para isso precisamos de novos profissionais, novos pensadores, novos aplicadores. Muda a lei, mas deve a mentalidade mudar para que o texto processual encontre respaldo na sua efetividade.

\section{REFERÊNCIAS}

ARonne, Ricardo. Direito Civil-Constitucional e Teoria do Caos Estudos Preliminares. Porto Alegre : Liv. Do Advogado, 2006. SAFE, 1996.

O princípio do livre convencimento do juiz. Porto Alegre :

. Razão \& Caos no Discurso Jurídico. Porto Alegre : Liv. do Advogado, 2010.

ÁVILA, Humberto. Teoria da segurança jurídica. 3. ed. São Paulo: Malheiros, 2014.

CANARIS, Claus-Wilhelm. Pensamento sistemático e conceito de sistema na ciência do direito. Trad. A. Menezes Cordeiro. Lisboa : Fund. Calouste Gulbenkian, 1989.

CHASE, Oscar G. Law, Culture, and Ritual: disputing systems in crosscultural context. New York: New York University Press, 2005.

DERRIDA, Jacques. A farmácia de Platão. São Paulo: Iluminuras, 1991. . Gramatologia. São Paulo: Perspectiva, 1998.

DIDIER JR., Fredie; BRAGA, Paulo Sarno; OLIVEIRA, Rafael Alexandria de. Curso de Direito Processual Civil: teoria da prova, direito probatório, ações probatórias, decisão, precedente, coisa julgada e antecipação dos

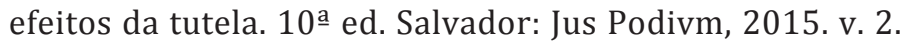


FILARDI, Hugo. Motivação das decisões judiciais e o Estado Constitucional. Rio de Janeiro: Lumen Juris, 2012.

FOUCAULT, Michel. Arqueologia das ciências e a história dos sistemas de pensamento. 2.Ed. Rio de Janeiro: Forense, 2005.

As palavras e as coisas. São Paulo: Martins Fontes, 2002.

FREITAS, Juarez. A interpretação sistemática do direito. São Paulo: Malheiros, 2004.

GADAMER, Hans-Georg. Verdade e método. 3. ed. Petrópolis : Vozes, 1999.

GARAPON, Antoine. Bem julgar: ensaio sobre o ritual judiciário. Tradução de Pedro Filipe Henrique. Lisboa: Instituto Piaget, 1997.

GLEICK, James. Caos - a criação de uma nova ciência. Rio de Janeiro : Campus, 1990.

GUASTINI, Ricardo. Das fontes às normas. Traduzido por Edson Bini. São Paulo: Quartier Latin, 2005.

HEIDEGGER, Martin. Ser e tempo. São Paulo: vozes, 2006.

HEISENBERG, Werner. A Ordenação da Realidade. Rio de Janeiro : Forense Universitária, 2009

MANDELBROT, Benoït. The fractal geometry of nature. S. Francisco : J. Wiley, 1982.

MARINONI, Luiz Guilherme. Teoria geral do processo. 8. ed. São Paulo: Revista dos Tribunais, 2014. v. I.

MARINONI, luiz Guilherme; ARENHART, Sérgio Cruz; MITIDIERO, Daniel. Novo Curso de Processo Civil: teroa do processo civil. São Paulo: Revista dos Tribunais,m 2015. v. I.

MORIN, Edgar. Saberes globais e saberes locais: um olhar transdiciplinar. Rio de Janeiro: Garamond, 2001.

MÜLLER, Friedrich. 0 novo paradigma do Direito: introdução à teoria e metódica estruturante. 3. ed. São Paulo: Revista dos Tribunais, 2012. PASCAL, Blaise. Pensamentos. São Paulo: Martins Fontes, 2001.

PASQUALINI, Alexandre Câmara. Hermenêutica e sistema jurídico. Porto Alegre: Liv. Do Advogado, 2000. 
PRIGOGINE, Ilya. 0 fim das certezas: tempo, caos e as leis da natureza. São Paulo: NESP, 1996.

SANTOS, Boaventura Souza. Um discurso sobre as ciências. 3. ed. São Paulo: Cortez, 2005.

SARTRE, Jean-Paul. o ser e o nada. Petrópolis: Vozes, 2007.

STEWART, Ian. Será que Deus joga dados? A nova matemática do caos. Rio de Janeiro: JZE, 1991.

THEODORO JÚNIOR, Humberto; NUNES, Dierle; BAHIA, Alexandre Melo Franco; PEDRON, Flávio Quinaud. Novo CPC: fundamentação e sistematização. Rio de Janeiro: Forense, 2015.

VARELA. 0 Erro de Descartes. Lisboa: Rosa dos Ventos, s.d. 